\title{
Psychological Injury and Law: Editorial on Practice Criteria
}

\author{
Gerald Young
}

Received: 20 December 2008 / Accepted: 16 January 2009/Published online: 12 March 2009

(C) Springer Science + Business Media, LLC 2009

\begin{abstract}
The area of psychological injury and law is one that is interdisciplinary, requiring knowledge in multiple areas. Psychologists should acquire the necessary background knowledge before working in it. At the same time, many clinicians encounter these types of cases. Credentialing bodies in states and provinces should consider establishing criteria for working in the area of psychological injury and law. Working groups in each jurisdiction can be established to help create these criteria. The journal Psychological Injury and Law (PIL) and its parent society, the Association for Scientific Advancement in Psychological Injury and Law (ASAPIL), can actively help the field of practicing psychology meet the objectives of this proposal.
\end{abstract}

Keywords Psychological injury · Law · Perspectives . Practice $\cdot$ Criteria

Daniel Bruns served as action editor for this article. Many thanks to Eric Drogin, Jacques Gouws, Andrew Kane, Douglas Salmon, and Brent Van Dorsten for their helpful comments on the text. The arguments and recommendations expressed in the editorial reflect the personal opinion of the author and should not be considered a society or journal position paper or policy.

The author's work has been supported by course leaves granted by both Glendon College and York University and editorial grants from Springer Science + Business Media.

In terms of possible conflicts of interest, the author has obtained most of his attorney referrals and psycholegal referrals from plaintiff rather than defense attorneys and assessment companies.

G. Young $(\bowtie)$

Department of Psychology, Glendon College, York University,

2275 Bayview Ave,

Toronto, ON, Canada, M4N 3M6

e-mail: gyoung@glendon.yorku.ca

\section{Introduction}

Psychological injury concerns diagnoses such as chronic pain, traumatic brain injury (TBI), and posttraumatic stress disorder (PTSD) after an event at claim, such as motor vehicle accidents (MVAs) or workers' compensation injuries. The journal Psychological Injury and Law (PIL) consists of seven sections, of which three specifically concern these three types of psychological injury. The disability or work, forensic psychology, and assessment sections of the journal serve to complement the three areas relating to TBI, PTSD, and pain. The law section of the journal concerns tort law, evidence law, regulations related to worker compensation, Social Security, disability policies, police and worker programs, veteran administrations, and related matters.

The goal of this journal, PIL, and its parent society, the Association for Scientific Advancement in Psychological Injury and Law (ASAPIL), is to educate and encourage best practices by psychologists dealing with clients presenting with psychology injuries. In particular, we adopt a scientifically informed approach to undertaking assessment or evaluation and in report writing, in providing treatment or other client services, and in dealing with any related legal aspects. We aim to be a middle-of-the-road organization that presents the state-of-the-art scientific knowledge and clinical practice considerations needed to function in the adversarial divide that marks the field.

Psychological injury and law is a new dynamic area that sits at the intersection of its seven major areas (law, forensic psychology, disability or work, PTSD or distress, pain, TBI, assessment). It also integrates concepts related to causality and causation. I maintain that the area of psychological injury and law deserves to be recognized as a distinct area of practice, especially because it integrates its contributing 
areas and related concepts. This editorial examines several issues related to the proposal, before arriving at recommendations, including what may constitute minimal criteria needed to practice in the area of psychological injury and law.

\section{Creating Rosters of Clinicians Practicing in Psychological Injury and Law or PIL}

Credentialing (licensing or certifying or registering) bodies in states and provinces should consider making the area of psychological injury an area of defined expertise. That is, they should consider requiring psychologists to meet explicit criteria both for assessment and treatment before they can be officially listed to practice in the area of psychological injury and law. At the same time, the credentialing of practitioners in psychological injury and law should be developed in a cautious manner. State or provincial credentialing bodies interested in pursuing the suggestion could, first, consider the formation of working groups in their jurisdiction to help clinicians master what is necessary. The journal PIL and the ASAPIL society can actively help the field of practicing psychology meet the objectives of this proposal.

To this end, this editorial includes, below, a tentative list of criteria to consider in establishing expertise in the area of psychological injury and law. This tentative listing of practice criteria for the area of psychological injury and law should be considered only a starting point and aspirational, meant to guide further reflection on the issues raised. Each of the items on the list of criteria presented requires more elaborate description, and each might have disadvantages and advantages that have to be considered. States and provinces that consider the present proposal worthwhile might proceed to investigate the criteria listed.

Once a state or province establishes its particular criteria for listing its members who demonstrate expertise in the area of psychological injury and law, psychologists already working on these types of cases should be considered to sufficiently meet these criteria, in a grandfathering process. Those not included in the grandfathering process and aiming to be listed in jurisdictions that adopt such criteria could then work toward being included on such lists of available practitioners.

It should not be assumed that all mental health professionals have the expertise to assess and treat cases of psychological injury, given the complexities of the cases. For example, new registrants or licensees will likely need further experience, training, and education according to the criteria listed. States and provinces might hesitate to consider the present proposal because of financial considerations. However, the costs to state and provincial boards in setting up rosters of practicing psychologists in PIL who meet the minimal criteria for the area would be limited, yet the advantages, as described, for psychologists, clients, and the public, may be great. It is expected that jurisdictions will refrain from developing anything more than lists of recognized criteria involving sufficient education training and experience to practice in the area of psychological injury and law.

A long-term objective of the journal and of the society is to head in the direction of establishing minimum national criteria for effective work in the area of psychological injury and law. Moreover, the journal and society are exploring the idea of creating a body that can bestow certification or diplomate status on those who can demonstrate that they meet the recommended criteria.

\section{Clinicians in PIL Differ From Forensic Psychologists}

Although this editorial is advocating that clinicians working in the area of psychological injury and law should be trained to meet minimum standards in their assessments and therapy, I am not advocating that they must meet the standards for forensic assessments, because this level of expertise is very different. Forensic psychologists who work in the area of psychological injury and law undertake comprehensive assessments that address civil legal issues arising from cases at claim, and they are not treating professionals in cases in which they have a forensic role. In particular, for cases going through an administrative process (e.g., an appeal of an initial rejection by insurance) or to court, forensic psychologists function as the proper evaluators.

Forensic psychologists and treating psychologists may both benefit from being listed on rosters of practitioners in the area of psychological injury and law. Normally, forensic psychologists have a general expertise in criminal and/or civil matters, but they may not have specific experience with psychological injury cases, nor knowledge of the particular local legislation and administrative requirements in dealing with such cases.

Treating clinicians may benefit from reaching the minimum criteria of PIL listing by what is gained in meeting the proposed criteria. Through the increased education, training, and experience, clinicians will be gaining a deeper understanding of the challenges of providing treatment within a medicolegal context. Moreover, they will serve their clients by better understanding systemic barriers, limitations of benefits, issues of apportionment, systemic challenges to overcome, and secondary gain.

The role of clinicians who work in the area of psychological injury and law is typically that of providing therapy and writing treatment plans and any reports requested to support them. The depth of requested reports varies from one jurisdiction and insurer or third party payor to the next. 
Normally, clinicians have sufficient knowledge to undertake competent assessment and treatment for the purposes required by their clients and the third parties. However, they may be limited in providing definitive statements about disability, causality, and other legally relevant matters in civil litigation, legislation, and regulations, unless otherwise trained.

Moreover, treating psychologists generally do not undertake complete evaluations to the same degree as forensic psychologists, nor would their conclusions be given great weight in any court because of the limits of their assessments relative to forensic psychologists. In contrast, a forensic psychologist who is trained in psychological injury and law can address these more complex legal questions that it may be unwise for treating professionals to address, for example, as a result of conflicts of interest in treating clients and then forming forensic opinions about them.

A comprehensive evaluation requires complete review of medical records - not just of the MVA or other events at issue but, also, of all medical or psychological care for years prior to the event. Usually, these are not made available to clinicians treating clients. For this and other reasons, such as their participation in the therapeutic process, evaluations undertaken by clinicians in present circumstances will carry limited weight in court.

By indicating that clinicians are or can become practitioners with expertise in the area of psychological injury and law, this editorial is not arguing that they should be considered practitioners with expertise for court purposes. That is for the courts to decide in each individual case. Rather, I maintain that with appropriate background, the expertise or specialized skills needed to undertake appropriate assessments for the purposes at hand and therapy with these types of patients is well within clinicians' grasp.

\section{Advantages of Listing PIL Psychologists in the Area}

To elaborate further, the argument is that clinicians who are sufficiently trained to work in the area of PIL should be considered more than front-line mental health professionals in cases of psychological injury. Many clinicians have the necessary training to provide opinions on multiple issues related to PIL, and others can supplement their skills to do so. The practitioners can render professional and supported opinions on (a) the validity of the symptoms, impairments, and disorders diagnosed, (b) disability status, (c) course, continuity, severity, and permanency of the injury, (d) effectiveness of the treatment that has been rendered, (e) client adherence to treatment, (f) causation of the injury and the degree to which there are other factors to consider other than the signal event at claim, and, therefore, (g) ultimate prognosis.
Perhaps these clinicians do not have forensic training, per se, but the scope of their training includes issues such as those mentioned, or, perhaps these clinicians can attain this scope with further education, training, and experience. Clinicians dealing with PIL work in rehabilitation, trauma, clinical psychology, health psychology, and other areas. Moreover, their general professional practice guidelines and ethical obligations deter them from advocating inappropriately and unethically for their clients at the expense of their perceptions about the validity of their client's psychological presentation. Also, it may be easier for psychologists to advocate for needed psychological and related treatment knowing the legal and insurance issues in the field.

Further, the argument is that psychologists working with these types of patients should be allowed by insurers and other third-party payors to undertake assessments that are more comprehensive than is usual right from first encounter (within the limits of good financial management for the payors). For example, psychologists working with clients expressing psychological injuries would administer the psychological instruments needed to detect degree of symptom expression, personality styles, and perhaps response biases that complicate assessment conclusions. If these instruments were used from the beginning of a case, baselines would be available from which to detect trends over time relevant to these issues. Therefore, for example, it would be easier to argue that catastrophizing had been a factor in a client presentation that included symptom exaggeration when early results related to this question revealed much along these lines.

With better initial assessments by trained treatment providers fresh after a psychological injury, both the client and system will benefit. Insurer Examinations (or Independent Medical or Psychological Evaluations (IEs)) are the checks in the system. If an insurer does not accept the report as submitted, IEs are requested. The better the initial assessment by the treatment provider, the more chance there is that the insurer will not ask IE psychologists to vet the report and associated treatment plan. Or, if an IE is requested after the more comprehensive assessments being advocated, the more likely it is that IE psychologists will accept the report and accompanying plan; failing this, it will be easier for the psychologist who submitted the report and plan to rebut the IE psychologist. Note that forensic psychologists should be heavily involved in these IEs, so that they might have increased referrals right from the beginning of a case and not just in later tort action.

\section{What Psychologists in Psychological Injury and Law Need to Know}

I am recommending to the psychology profession that psychologists who meet specified criteria should be 
officially listed as eligible to work with cases of psychological injury. The boards of state and provincial psychology associations and credentialing bodies should investigate the minimum criteria needed for work in the area of PIL and enact changes to their governing rules and regulations consistent with the present recommendation. This will reward clinicians who have studied and trained to meet these criteria and it will serve to protect the public. At the same time, it will serve the legal profession well by ensuring that mental health professionals in the area are qualified to deal with such cases right from first encounter with psychologists.

How could state and provincial credentialing bodies proceed to implement the present recommendation? It is insufficient to suggest that credentialing boards adopt the most recently available version of local or national Specialty Guidelines for Forensic Psychologists because these standards go beyond what are the minimal criteria for practice in the area of psychological injury and law. Rather, work particular to the area of PIL must be undertaken. To begin, state and provincial psychological associations could establish informal working groups related to psychological injury and law. Then, the groups could work toward organizing Special Interest Groups that are intersectional or divisional, cutting across different specializations. Leading psychologists and attorneys in these local jurisdictions could collaboratively write briefs and articles on local laws and regulations that govern practice in the area, preparing the way for enactment of appropriate changes to rules and regulations governing criteria to practice in the area.

What particularities do psychologists need to consider in dealing with complainants with psychological injuries following events at claim? Health professionals in the area of psychological injury and law, by definition, are interdisciplinary or knowledgeable in multiple areas. This applies to within psychology, across its different areas, and not only in terms of the relationship of psychology to law. For example, in our field, psychologists need a refined knowledge of brain-behavior and of body-behavior relationships, even if they are not neuropsychologists. They have to know well the effects of trauma on patients and the influence of preexisting trauma, if any. They have to know how to work in the rehabilitation context, which often involves integrating teams of professionals. They must consider general health psychology issues, psychoneuroimmunology, and so forth. Often, family and significant others are involved in a systems focus in treatment. Rehabilitation could include return to work issues or, to the contrary, adjustment to disability. Psychologists in this area must understand adequately the legal issues, tort and evidence law, the specialized language of attorneys and legal cases, and so forth.
In the following, this editorial lists important questions about the area that psychologists who are wishing to practice or are already practicing in the area should be addressing. Are there differences in typical symptom expression for one type of trauma compared to another, for example, for motor vehicle accident compared to assault or rape? Do the psychologists understand nuances in critical terminology, for example, in terms of definitions of impairments, disorder, and disability? Do they appreciate that the tests that they choose to use in assessments, where feasible, should be chosen because they are appropriately normed for these types of complainants? What should psychologists do when needing such tests for minority and other culture and language groups? Are diagnoses that are controversial in some jurisdictions equally controversial in others, such as PTSD? Is chronic pain considered compensable to the same degree as other conditions? How is postconcussive syndrome due to mild TBI considered in the state or province, for example, in terms of possible pathophysiological and psychological causation? What state or provincial case law decisions speak to practice in the area of psychological injury and law? Do these decisions differ noticeably in terms of national trends or trends in neighboring or similar states? How is causality defined in terms of legal standards, (e.g., material cause, the "but for" test)? Are there concepts such as a "thin skull"? What are some of the legal thresholds involved for suing in tort? How are professional sources (such as medical guides) used to determine the presence of permanent impairment, and are they valid? What education, training, and experience do psychologists need to demonstrate in order to assess and to treat such clients, given the complexities implicit in the types of questions posed?

\section{Recommended Practice Criteria for Practicing in the Area of Psychological Injury and Law}

What practice criteria would be needed to meet minimal standards of professional practice in the area of psychological injury and law? This editorial maintains that minimal standards in PIL should include appropriate training, supervision, continuing education and reading, familiarity with commonly used instruments, and familiarity with relevant legislation and regulations. Specifically, relevant minimal practice criteria in the area of PIL should be built around the following ten areas.

1. Some supervision with a practitioner with PIL expertise.

2. Some continuing education participation.

3. Some reading, such as with the present journal and various books, e.g., by ASAPIL members. 
4. Some learning of instruments in the area that deal with PTSD, pain, and, if neuropsychologists, cognitive evaluations that may be relevant. Of course, practitioners would have to know instruments related to malingering and other response threats and biases. Because practitioners get generic licenses, they should already be familiar with many of these. The question is whether a practitioner knows what tests to use together as part of a precise assessment related to the issues at hand in such cases.

5. Some learning of forensic assessment procedures and practices, for civil rather than criminal questions, and limited to psychological injury.

6. Some learning of legal issues, related to evidence law, tort law in their jurisdictions, with important case law. Knowledge of critical legal terms, e.g., thresholds for disability determinations.

7. Knowledge of the adversarial nature of the work in the area, how to avoid the biases and pressures, and how to meet professional requirements not to do harm, to uphold professional practice requirements and ethics, etc.

8. Some learning of the specific therapeutic schools, techniques, and procedures used with the client population in this area.

9. Some learning of the effect of physical injury, the stress that accompanies physical and psychological injuries, the physiological influences of such injuries, and so forth, in body-behavior relationships.

10. Some knowledge of systemic influences on the patient population, ranging from the professional to the familial, to the constant evaluations and to dealing with teams of treatment providers, to insurance and tort-related issues, to loss of work and reduced or absent income or benefits, and to the influences of potential financial gain and secondary gain.

An alternative would be to take upgrade courses at universities or institutes, participate in externships, and so forth. The programs involved should be structured to cover the types of criteria listed above.

\section{Conclusions}

The journal PIL and its parenting body ASAPIL are ready to help practitioners and state and provincial organizations toward realizing the recommendations being made. The society is seeking to establish working groups in each state, province, and foreign country interested in the area of psychological injury, with an aim toward the creation of local branches or chapters of ASAPIL.
Ultimately, ASAPIL may advocate for the creation of a sister organization, Association for the Professional Accreditation in Psychological Injury and Law (APAPIL). It would certify that the particular state or provincial requirements for work in the area meet our minimum requirements for inclusion on such lists of qualified practitioners in PIL. At the outset, this organization would not be a credentialing body. Nevertheless, it will help practitioners inform their clients and referral sources that they have met minimal standards in professional competence in the area of psychological injury and law. Eventually, the sister organization could move toward becoming a credentialing body that confers diplomate status. This step could be undertaken only after meticulous investigation and planning, through work with national and local psychological and other mental health organizations.

Nearly all states and provinces have generic licenses. They require that psychologists keep the board informed of their areas of practice and justify in writing the addition of new areas of practice. Psychologists are normally asked what areas of practice they are competent in when first licensed. They are required to notify the board and document additional education or training, if or when there is an expansion into additional areas. It is the individual psychologist's responsibility to keep the board informed of his or her areas of practice.

Moreover, it is not common for psychologists to be listed on rosters according to any professed area of expertise from a licensure standpoint. In addition, even if there are such rosters in a particular jurisdiction, the question becomes what are the minimal criteria for adding PIL work to one's practice competence.

Although many treating practitioners are competent in the area of psychological injury and law, more psychologists can acquire the competence and others already working in the area can improve the quality of services that they provide. For example, counter-transference, the requirement to be beneficent and nonmaleficent, and numerous other factors prevent the treating clinician from being sufficiently independent to state his or her conclusions to a reasonable degree of psychological certainty in any court-related situation. Also, psychologists, as well, have many pressures and biases to which they can succumb, for example, related to the adversarial nature of the area. Whether he or she is a forensic or a clinical psychologist, a clinician doing this type of work can be trained to avoid the pitfalls involved, for example, blindly advocating for a client. Having psychologists meet the type of minimal criteria presented in the editorial for practicing in PIL will ensure that practitioners in the area understand all the pressures and biases acting on them, from counter-transference to legal pressures, both in terms of their roles as assessors and therapists. 
To summarize, this editorial is advocating that treating clinicians should aspire to meet minimum standards in their assessments and therapy, as they deal with clients right at the onset of a psychological injury, improving the quality of service provided. The argument is not that clinicians should replace forensic psychologists, for example, in evaluations for tort purposes later on in a case. At the same time, forensic psychologists can profit from specified training in the area of psychological injury and law, if their civil caseload does not include these types of clients and they wish to add them, or if they have such cases but wish to obtain further specified training in the area. States and provinces can create mechanisms for listing psychologists who are qualified to assess and to treat cases of psychological injury by having met appropriate minimal rigorous standards, such as ones based on the present recommendations. 